the oesophagus, after which time she sud-1 denly ejected some matter (from the larynx, I suppose), and gradually became capable of swallowing again, so that in the course of about a week she returned to her place.

In the following September she had a similar attack to those in 1837 and 1838 , which soon yielded to a large bleeding, and she had the same kind of attack and the same remedy in January, 1810, and in $\mathrm{Fe}$. bruary, 1841. I think the blood taken in 1841 only was buffy, and that was also cupped. She was at the sea-side some weeks during the last summer.

From that illuess in March, 1839, to this time, she has been often troubled with the breaking of the same abscess in a trifling degree, and occasionally with offensive discharge from it, on which accountshe is now anxious to be admitted into some hospital, in the hope of having a cure effected. I am, Sir, yours respectfully,

East Retford, April 12, 1811.

$$
\text { W. Allison. }
$$

\section{RESTRAINT OF LUNATICS.}

"Sare me from my friends."

\section{To the Editor of Tur LanceT.}

SIR :- Faving just read in your Publication of the 20 th ultimo an elaborately-written letter signed "Medical Superintendent," on "the subject of the humane system of treatment of the insane," in which the writer quotes a portion of a paragraph from a report of mine of the Belfast District Lunatic Asylum of March, 1840, and which, if taken per se, would lead to the inference that $I$ was an advocate ex cathedra, for the total abolition of restraint in every case of lunacy whatever, I beg leave accordingly to crave a corner in your valuable Periodical, in order to prevent such a misapprehension, by stating that I am not a disciple of the tutai abolition school (as may be seen by a reference to the report in question), ny deliberate opinion on this head being that instrumental restraint-by which I by no means intend "iron hobbles, chains, beatings, or bruisings," such as Mr. Hill, of Lincoln, averred to be the species of restraint in common use in English lunatic asylums-cannot, either with safety or humanity, be dispensed with altogether; but, on the contriry, that its occasional and judicious application is not only unavoidable in many instances, but is a most valuable curative means, if confided to humane and professionaliy-educated su. perintendents, who, considering the great and unceasing responsibility of their ardinous office, ought assuredly to be permitted freeagency as to its use or disuse, equally so as in the prescribing of the most fitting $m_{b}$. dical treatment for such unhappy, but very perplexing, cases as require restraint being had recourse to. Surely it will not be denied that such distingnished and ex. perienced men in the management of the in. sane, as Dr. Corsellis (Wakefield), Dr. Kirk. man (Suffolk), Dr. Blake and Surgeon Powell (Nottingham), Drs. Browne, Hut. chinson, M'Kinnon, Malcolm, \&c. \&c., of the Scotch asylums, should uot be entrasted with this free-agency? And is their huma. nity to be called into question by anony. mous writers, forsooth, because, in the exer. cise of a sound discretion, they summon re. struint to their aid? Away with such mock teuderness, such morbid sympathy and sen. sitiveness for the furious insane: through evil report and good report, I trust the above individuals will continue to pursue the even tenor of their way, and by so doing be preserved from the dangerous hallucinations of that mono-mania of the present day, nos. restraintism, which, of all others, calls loudly for prompt and close restraint, so as to keep its unfortunate patients withn the bounds of moderation. As the report of this asy. lum for March, 1841, is about beiug printed, in which the subject of this note is again sbortly discussed (a copy of which will, with much pleasure, be forwarded to you), I shall not further trespass on your indal. gence by needlessly enlarging on it, and beg to remain, Sir, your most obedient servant, Robert Stewart, M.D., Resident Superintendent.

Belfast District Asylum, April 6, 1841.

\section{RESPONSIBILITY OF MEDICAI، PRACTITIONERS.}

\section{To the Editor of THE LaNCET.}

Sir :-As I doubt not that there are some of the members of our profession as unaware of the responsibility of the medical practitioner in certain cases, as $I$ confess myself to have been, $I$ beg your insertion in THE Lancer of the accompanying case.

On the 15th of February I was called by the landlady of a house in this neighbour. hood to see one of her lodgers, Miss B-, aged 70 , who was sutfering from a spitting of blood. I prescribed for her some medicine containing diluted sulphuric acid, and in the evening when I called, I found that the spitting of blood had entirely ceased: the mixture was costinued.

Feb. 16. The hamorrhage has not re. turned; the acill in the mixture was reduced in quantity. She expresses herself as much better, and I requested the attendant to let me know if the spitting of blood recurred.

18. The symptoms were entirely relieved. My patient told me, that Mrs. L_-, the friend who had supplied her with the rabbitpie, which was then on the table, and of which she was eating, would become re. sponsible to me for my attendance.

24. On calling to-day I found my patient to be quite recovered; she requested, how: ever, that another mixture might be sent, as 
she had become stronger from the use of the former. Her bowels not being sufficiently open, six powders, composed of rhubarb and magnesia, were also prescribed for her.

I now, for the first time, heard, that the attendant, Mrs. L-, of whom she had spoken, came but twice or thrice a-week; and I expressed my opinion to the landlady, who usually accompanied me to the sick room, that this was not sufficient, and requested that Mrs. $L_{1}{ }_{-}$might be written to. At this period $I$ considered my attendance on Miss $B$ - to be finished, as she was then completely recovered.

About the 4 th of March Mrs. L called on me, and inquired if Miss $B$ might be removed to Chelsea? I then gave it as my opinion, that having been in bed during the whole winter, it wonld be very imprudent to move her so suddenly; that she was to be accustomed to the change, by getting out of bed every day, and $I$ ex. pressly said, "that the cook was more needful to her than the doctor, and that she required nourishment;" an observation which I considered to be sufficient to a person who, I had been given to understand, was paying the lodging, and providing for Miss $B$ -

The character of Miss B- has been constantly to misrepresent her concerns to those about her; and any inquiries relating to her wants always offended her highly. It is from this cause that solittle was kuown of her real state.

On the 10th of March, at eight P.M., I was called to see Miss $\mathbf{B}$-_; she had been dead apparenlly about two hours; and I was told that no person had seen or been near her during the entire day.

Two days subsequently, at my desire, an inquest was held. On the morning of the inquest Mrs. L- called on me; though poor herself, a widow, with a large family, she had for years allowed Miss B-, the friend of her mother, five shillings a-week. To her surprise, she had learnt that morning that four shillings and threepence per week had been paid for her lodging only; and, to use Mrs. L_-'s own explession, "Miss B- was so close, that she had never let me know her poverty."

As ninepence weekly is too small a pittance to provide food and fire, Mrs. Lsupposes that her friend had existed on the proceeds of her furniture, which she had disposed of piece by piece.

These latter facts became known only after the death of the subject of this paper.

The inferred dismissal of the medical attendant on the 2.1h of February; the bevefit she experienced under his treatment; the advice given of increased nourishment to the party most qualified, and apparently most willing to afford it; and the expiration of fourteen days between the time of his last seeing her and her death, would seem suffi. cient to have exonerated the medical at- tendant from all blame; yet an opinion was expressed by the coroner's jury, though not recorded in their verdict, that the responsibility of a practitioner was not restricted by his medical attendance; that it was a portion of his duty to inquire into and know his patient's wants; and in the present case to have required assistance from the poorhouse of the parish.

I need make no comment on the preceding case, its circumstances will show how necessary it is for the practitioner to be aware of the various duties required of him. I have the honour to subscribe myself your obedient servant,

Grorge Wilson, Surgeon. 100, Great Portland-street, March 30.

\section{UNIVERSITY COLLEGE HOSPITAL.}

\section{CONTUSED AND LACERATED WOUND OF THE THUMB.}

T. M., aged 24, was admitted January 8 , 1841. He is a healthy, well-made man, with a florid complexion; by trade a plumber; has been shooting all day, and on his return, about two hours ago, proceeded to discharge the contents of the gun which had been loaded by another person, and as, he thinks, overcharged. The barrel burst and injured his left hand, which was held some distance along it. On admission, two hours after the accident, it was found that he had received a severe, lacerated and contused wound of the ball of the left thumb, extending from the cleft between the thumb and index finger, nearly to the base of the metacarpal bone; the cuticle of the palm was considerably blackened, and stripped off in several places; the muscles composing the ball of the thumb were much torn and bruised; the head of the metacarpal bone was bare, and the attachment of muscles to the upper part of that bone separated; the first phalanx was partially dislocated from the head of the metacarpal bone, the ligaments between the two bones being extensively divided, and the joint completely opened; the bones of the thumb were not fractured, and the long tendon appeared to remain uninjured, as the patient could slightly flex and extend the injured part; there was slight oozing of blood at the time of admission; patient's face somewhat flushed; not much pain. As the bones were entire, and as the thumb conld still be moved a Iittle, the house-surgeon, Mr. J.P. Potter, determined on attempting to save the part.

[It was evident that there would be considerable sloughing and suppuration about the parts; but this could not be prevented by removing the thumb with the metacarpal bone, as the bruised and lacerated part of the palm would still be left; and union of the flap by the first intention could not be expected.] 